Vol. 10 No 012019

e-issn : 2622-0148, p-issn : 2087-0035

\title{
ASUHAN KEPERAWATAN PEMENUHAN KEBUTUHAN OKSIGENASI PADA PASIEN ASMA BRONKHIAL DI RSUD. HAJI MAKASSAR
}

\section{NURSING CARE FULFILLS THE OXYGENATION NEEDS OF BRONCHIAL ASTHMA PATIENTS AT THE MAKASSAR HAJI GENERAL HOSPITAL}

\author{
Hardiyanti Anastasia Yusuf', Sukma Saini², \\ Sri Wahyuni Awaluddin ${ }^{3}$ \\ 1 Program Studi DIII Keperawatan Poltekkes Kemenkes Makassar \\ 2,3 Jurusan Keperawatan Poltekkes Kemenkes Makassar \\ *) E-mail korespondensi : ogi.badisca@gmail.com Nomor Hp : 085242663061
}

\begin{abstract}
ABSTRAK
Asma Bronkhial adalah penyakit pernapasan pada jalan napas obstruktif intermitten, reversibel dimana trakea dan ronchi berespon secara hiperaktif terhadap stimulus tertentu. Pasien ini mengalami proses peradangan di saluran napas yang mengakibatkan peningkatan responsive dari saluran napas penyakit penyebab terganggunya kebutuhan dasar manusia oksigenasi kurang dari kebutuhan. Pemenuhan kebutuhan oksigenasi adalah bagian dari kebutuhan fisiologi menurut Maslow yang sangat penting dalam kelangsungan hidup manusia. Tujuan penulisan studi kasus ini adalah untuk menggambarkan asuhan keperawatan pemenuhan kebutuhan oksigenasi pada pasien Asma Bronkhial di ruang perawatan Rumah Sakit Umum Daerah Haji Makassar. Metode yang digunakan adalah penelitian studi kasus berupa pendekatan asuhan secara kompherensif sesuai proses keperawatan/pendekatan asuhan keperawatan fokus pada prosedur rencana keperawatan. Hasil penelitian menunjukkan dari pengkajian didapatkan hasil pasien I, II dan III sama-sama menderita penyakit asma bronkhial dengan gejala yang sama pada pasien I dan II yaitu sesak napas disertai nyeri dada dan batuk berdahak disertai pilek, ronchi sedangkan pasien III hanya dengan. Sedangkan diagnosa keperawatan yang ditetapkan untuk pasien I, II, III adalah: pola napas tidak efektif dengan keluhan sesak napas disertai nyeri dada dan terdengar wheezing. Pada tahap pelaksanaaan tindakan keperawatan didapatkan kesesuaian dengan rencana yang telah disusun pada ketiga subjekbahwa Kesimpulan studi kasus menunnjukkan bahwa dari ketiga pasien didapatkan asuhan keperawatan pada pasien pertama dan ketiga teratasi sedangkan pasien kedua tidak teratasi karena pemenuhan kebutuhan oksigensi dalam tubuh belum terpenuhi.
\end{abstract}

Kata Kunci : Asuhan Keperawatan, Oksigenasi, Asma Bronkhial

\section{ABSTRACK}

Bronkhial asthma is a respiratory disease in the intermittent obstructive airway, reversible where the trachea and ronchi respond hyperactively to certain stimuli. This patient experiences an inflammatory process in the airways which results in increased responsiveness of the airways to diseases which cause disruption of basic human needs oxygenation is less than needed. Fulfiling oxygenation needs is part of Maslow's physiological needs which is very important in human survival. The purpose of writing this case study is to describe nursing care to fulfill oxygenation needs in Bronkhial Asthma patients in the treatment room of the Makassar Haji General Hospital. The method used is case study research in the form of comprehensive care approaches according to the nursing process I nursing care approach focusing on the nursing plan procedure. The results showed that of the three patients, nursing care in the first and third patients was resolved while the second patient was not resolved because the fulfillment of the need for oxygen in the body had not been fulfilled.

Keywords : Nursing Care, Oxygenation, Bronkhial Asthma.

\section{PENDAHULUAN}

Manusia merupakan makhluk yang unik dengan beragam karakteristik dan memiliki kebutuhan - kebutuhan yang berperan penting dalam kelangsungan hidupnya. Salah satu kebutuhan fisiologis dasar yang sangat penting yaitu oksigen. Oksigen berperan penting dalam sistem pernapasan. Pada system pernapasan terdapat berbagai macam 
Vol. .... No......20....

e-issn : 2622-0148, p-issn : 2087-0035

penyakit, salah satunya adalah Asma Bronchial. Asma bronchial biasanya dikenal sebagai suatu penyakit yang ditandai dengan adanya intermitten yang muncul sebagai respon akibat paparan terhadap suatu zat iritan atau alergen (Margaret Varnell Clark, 2013)

Menurut Global Initiative for Asthma (GINA) hampir 300 juta jiwa di seluruh dunia menderita penyakit asma. Prevalensi tertinggi ditemukan di negara Britania Raya, rata-rata sekitar 1 dari 15 penduduk menderita asma. Hal ini menjadi salah satu penyebab utama pasien masuk Rumah Sakit di Britania Raya sekitar 75.000 pasien pertahunnya, dengan demikian menunjukkan bahwa diperkirakan 1 dari 4 orang memiliki asma berat atau asma sedang yang akan membaik jika melakukan terapi yang adekuat (Margaret Varnell Clark, 2013).

GINA juga memperkirakan bahwa pada negara berkembang yaitu, di Afrika, Amerika Tengah dan Selatan, Asia dan Pasifik Basin terus mengalami peningkatan yang signifikan. Prevalensi tertinggi diantaranya terdapat di Afrika dengan lebih dari 50 juta penduduk kemudian diikuti oleh Amerika Selatan dan Tengah dengan lebih dari 40 juta penduduk (Clark, Margaret Varnell, 2013).

Data RISKESDAS (2018) menyatakan di Indonesia, prevalensi penyakit asma mencapai 2,4 \% penduduk dari seluruh total penduduk. Prevalensi terdapat di provinsi Daerah Istimewa Yogyakarta sekitar 4,5\%, sedangkan di provinsi Sumatera Utara menjadi daerah terkecil penderita asma sebesar $1,0 \%$. Di Sulawesi Selatan, penderita asma mengalami penurunan dari tahun 2013 sekitar 7,0\% menjadi $2,5 \%$ orang. Sedangkan proporsi kekambuhan asma dalam 12 bulan terakhir tahun 2018 pada penduduk semua umur di Indonesia mencapai 57,5\%. Proporsi terdapat di provinsi Aceh sekitar 68,9\%, sedangkan di provinsi Daerah Istimewa Yogyakarta menjadi daerah terkecil penderita yang mengalami kekambuhan asma sekitar 46,1 \%. Di Sulawesi Selatan, proporsi kekambuhan asma menduduki posisi ke 11 dari 34 provinsi dengan penderita sebesar $62,5 \%$.

Data yang didapatkan dari RSUD Haji Makassar pada 2 tahun terakhir diketahui jumlah kasus asma bronkhial tahun 2017 yaitu 50 kasus yang terdiri dari perempuan 28 kasus, laki-laki 22 kasus dan pada tahun 2018 terdapat 63 kasus yang terdiri dari perempuan 27 kasus, laki-laki 36 kasus dengan 1 kasus meninggal. Dari data tersebut, dapat disimpulkan bahwa penyakit asma bronkhial di RSUD Haji Makassar terjadi peningkatan dari tahun 2017 sampai 2018. (Rekam Medis RSUD Haji Makassar, 2019)

Penyakit asma memiliki gejala yang berbedabeda pada setiap orang, gejala asma pada saluran pernapasan terdiri dari triad, yaitu : dyspneu, batuk, dan mengi/wheezing. (Somantri, 2012). Hal ini berkaitan erat dengan kebutuhan oksigenasi yang merupakan kebutuhan dasar yang paling vital dalam tubuh manusia, karena berperang penting dalam proses metabolisme dalam tubuh. Jika suplay oksigen berkurang dalam tubuh bisa mengakibatkan terjadinya gangguan didalam tubuh yang bisa sangat berakibat fatal dengan berujung pada kematian. (Wahid, 2008). Kebutuhan oksigenasi harus selalu terpenuhi karena berhubungan erat dengan terjadinya kekambuhan penyakit asma. Oleh karena itu, kekambuhan penyakit asma seharusnya dicegah dengan menghindari alergen yang menyebabkan gejala asma muncul, tetapi apabila tidak dicegah kekambuhannya akan mengakibatkan kematian.

Kematian pada pasien asma dapat terjadi akibat suplay oksigen dalam tubuh tidak terpenuhi, allergen, stress dan cuaca yang mengakibatkan antigen pada permukaan sel mast/basofil lalu mengeluarkan mediator : histamine, platelet, bradikinin kemudian permiabilitas kapiler meningkat yang mengakibatkan edema mukosa, sekresi produktif, kontriksi otot polos meningkat kemudian spasme otot bronkus meningkat yang mengakibatkan terjadinya penyempitan/obstruksi proksimal dari bronkus pada tahap ekspirasi dan inspirasi, setelah itu akan muncul mucus berlebih, batuk, wheezing, dyspneu, yang mengakibatkan tekanan parsial $\mathrm{O} 2$ dialveoli menurun menyebabkan penyempitan jalan pernapasan mengakibatkan kebutuhan $\mathrm{O} 2$ meningkat menyebabkan terjadi hiperventilasi kemudian terjadi retensi 02 dan menyebabkan terjadinya Asidosis Respiratorik. Kondisi ini dapat dicegah dengan menghindari faktor pencetusnya (NANDA, 2015).

Perhimpunan Dokter Paru Indonesia (2015) menyatakan penatalaksanaan asma terdapat tujuh komponen, yaitu : edukasi, menilai dan monitor berat asma secara berkala, identifikasi dan mengendalikan faktor pencetus, merencanakan dan memberikan pengobatan jangka panjang dengan tindakan kolaboratif bersama tim kesehatan lainnya seperti pemberian obat-obatan I inhalasi / massage pernapasan, menetapkan pengobatan pada serangan akut, kontrol secara teratur, dan pola hidup sehat. (NANDA, 2015)

Berdasarkan uraian tersebut diatas, maka penulis tertarik untuk melakukan penelitian yang berjudul : "Asuhan Keperawatan Pemenuhan Kebutuhan Oksigenasi Pada Pasien Asma Bronkhial di RSUD. HAJI MAKASSAR."

\section{BAHAN DAN METODE}

Jenis penelitian deskriptif dalam bentuk studi kasus yang merupakan penelitian untuk mengumpulkan dan menggambarkan informasi mengenai status subyek penelitian kemudian menghimpun dan menganalisis data berkenan dengan kasus yang diangkat selanjutnya dituangkan dalam bentuk asuhan keperawatan. Desain yang dipilih adalah studi kasus berupa pendekatan asuhan 
Vol. .... No......20....

e-issn : 2622-0148, p-issn : 2087-0035

keperawatan secara komrehensif sesuai proses keperawatan (pengkajian, diagnosis, intervensi, implementasi dan evaluasi). Populasinya adalah semua pasien yang mengalami masalah pemenuhan kebutuhan oksigenasi pada pasien penyakit asma bronchial di Ruangan Rindra Sayang 1 RSUD Haji Makassar pada bulan juni dengan sampel penelitian dari tanggal $14-21$ juni 2019 berjumlah tiga pasien yang dipilih menjadi subjek. Variabel independen adalah gangguan pemenuhan kebutuhan oksigenasi dan variabel dependen adalah pasien asma bronkhial.

Definisi operasional variabel penelitian sebagai berikut :

1. Asuhan keperawatan adalah suatu proses keperawatan dengan menggunakan pendekatan yang sistematis untuk bekerja sama dengan klien atau pasien antar individu, kelompok dan komunitas yang dimulai dari pengkajian, diagnosis, intervensi, implementasi dan evaluasi.

2. Pemenuhan kebutuhan oksigenasi adalah bagian dari kebutuhan fisiologis menurut Maslow. Kebutuhan ini sangat penting dalam kelangsungan hidup manusia.

3. Asma bronkhial adalah penyakit pernapasan pada jalan napas obstruktif intermitten, reversibel dimana trakea dan ronchi berespon secara hiperaktif terhadap stimulus tertentu.

Tekhnik pengumpulan data pada penelitian ini adalah wawancara atau anamnesis, observasi (pengamatan) dan pemeriksaan fisik. Analisa data yang telah dikumpulkan akan diawali melalui tahapan asuhan keperawatan dengan tahap sebagai berikut : analisis hasil pengkajian, diagnosis kebutuhan oksigenasi, intervensi, implementasi dan evaluasi keperawatan. Etika studi kasus yaitu informed concent, confidentiality (kerahasiaan) dan anonymity (tanda nama).

\section{HASIL DAN PEMBAHASAN}

Pada bagian ini, penulis akan membahas mengenai korelasi yang didapatkan antara konsep dasar teori maupun penelitian terdahulu dengan laporan kasus asuhan keperawatan pemenuhan kebutuhan oksigenasi pada pasien asma bronkhial yang dirawat di RSUD Haji Makassar.

1. Pengkajian Keperawatan

Pengkajian keperawatan dilakukan secara komprehensif dengan metode wawancara atau dengan pengamatan secara langsung dengan mengikuti perkembangan pasien.

Dari pengkajian didapatkan hasil bahwa pasien I, II dan III sama-sama menderita penyakit asma bronkhial dengan gejala yang sama pada pasien I dan II yaitu sesak napas disertai nyeri dada dan batuk berdahak disertai pilek, ronchi sedangkan pasien III hanya dengan keluhan sesak napas disertai nyeri dada dan terdengar wheezing. Hal ini didukung dengan manifestasi klinis asma bronkhial menurut Fadila (2013) diantaranya adalah sesak napas, nyeri dada, batuk berdahak disertai pilek, wheezing, ronchi.

Di tinjau dari teori dan penelitian sebelumnya, menurut Tika Achriani (2018) mengatakan bahwa gejala asma bronkhial yang sering timbul yaitu sesak napas disertai nyeri dada.

2. Diagnosa Keperawatan

Berdasarkan pengkajian yang telah dilakukan, peneliti menegakkan sebuah diagnosa keperawatan untuk pasien I, II, III yaitu : pola napas tidak efektif (Standar Diagnosis Keperawatan Indonesia, 2016).

Dari proses pengkajian didapatkan data dari pasien dan keluarga pasien bahwa pasien I, II merasa sesak napas disertai nyeri dada dan batuk berdahak disertai pilek sedangkan pasien III hanya merasa sesak napas disertai nyeri dada. Hal inilah menyebabkan tidak efektifnya pola napas pasien.

3. Intervensi Keperawatan

Perencanaan keperawatan yang biasa disebut intervensi keperawatan merupakan segala treatment yang dikerjakan oleh perawat yang didasarkan pada pengetahuan dan penilaian klinis untuk mencapai tujuan (outcome) yang diharapkan (PPNI, 2018).

Intervensi yang dilakukan pada pasien I, II dan III yang pertama : pemeriksaan tanda-tanda vital karena terjadi perubahan keadaan umum. Dalam teori Harmoko \& Sujono Riyadi (2012) bahwa salah satu pemeriksaan fisik yang dilakukan yaitu pemeriksaan tanda-tanda vital yang terdiri mengukur tekanan darah, mengukur suhu, menghitung denyut nadi dan menghitung pernapasan.

Kedua : memonitor frekuensi, kedalaman napas dan bunyi napas tambahan pasien. Pada teori Tarwoto, Wartonah (2015) bahwa dalam pemeriksaan fisik pernapasan yang perlu diperhatikan yaitu frekuensi napas, kedalaman napas dan bunyi napas tambahan karena untuk mengetahui adanya gangguan pola napas.

Ketiga : memberikan posisi semi fowler pada pasien. Pada teori PPNI (2018) dalam buku Standar Intervensi Keperawatan Indonesia bahwa dalam intervensi manajemen asma perlu dilakukan tindakan terapeutik yaitu memberikan posisi semi fowler 30 $45 \%$.

Keempat : memberikan oksigen pada pasien. Pada teori PPNI (2018) dalam buku Standar Intervensi Keperawatan Indonesia bahwa dalam intervensi manajemen asma perlu dilakukan tindakan terapeutik yaitu memberikan oksigen sesuai kebutuhan pasien untuk mempertahankan $\mathrm{SpO}_{2}>$ $90 \%$.

Kelima : memberikan terapi nebulizer pada pasien. Pada teori PPNI (2018) dalam buku Standar Intervensi Keperawatan Indonesia bahwa 
Vol. .... No......20....

e-issn : 2622-0148, p-issn : 2087-0035

memberikan terapi nebulizer untuk mencairkan secret dan memperlebar jalan napas.

Keenam : berkolaborasi pemberian obat pada pasien. Pada teori PPNI (2018) dalam buku Standar Intervensi Keperawatan Indonesia bahwa berkolaborasi pemberin obat pada pasien untuk mempermudah atau mempercepat proses pengobatan.

Ketujuh : mengajarkan mengidentifikasi dan menghindari pemicu pada pasien. Pada teori PPNI (2018) dalam buku Standar Intervensi Keperawatan Indonesia bahwa mengajarkan mengidentifikasi dan menghindari pemicu pada pasien untuk mencegah terjadinya kekambuhan asma bronkhial.

4. Implementasi Keperawatan

Menurut Persatuan Perawat Nasional Indonesia (PPNI) tahun 2018 bahwa pelaksanaan atau tindakan keperawatan yang dikenal dengan implementasi keperawatan merupakan suatu perilaku atau aktivitas spesifik yang dilakukan oleh perawat dalam mengimplementasikan intervensi keperawatan.

Penulis melakukan tindakan keperawatan sesuai dengan rencana yang telah disusun pada ketiga subjek yaitu memonitor tanda-tanda vital pasien, hasilnya tanda-tanda vital pasien subjek I TD : 120/80 mmHg, N : 88 x/menit, $S: 36,3^{\circ} \mathrm{C}, \mathrm{P}: 18 \mathrm{x} /$ menit, subjek II TD : 120/80 mmHg, N : 90 x/menit, $S$ : $36^{\circ} \mathrm{C}, \mathrm{P}: 26 \mathrm{x} /$ menit dan subjek III TD : 120/80 $\mathrm{mmHg}, \mathrm{N}: 86 \mathrm{x} / \mathrm{menit}, \mathrm{S}: 36,4^{\circ} \mathrm{C}, \mathrm{P}: 18 \mathrm{x} /$ menit.

Memonitor frekuensi, kedalaman napas dan bunyi napas tambahan, hasilnya subjek I frekuensi napas 18 kali permenit, kedalaman napas baik dan tidak terdapat suara napas tambahan, subjek II frekuensi $26 \mathrm{x} /$ menit, kedalaman napas baik dan terdapat bunyi napas tambahan yaitu ronchi. Subjek III frekuensi $18 \mathrm{x} /$ menit, kedalaman napas baik dan tidak terdapat suara napas tambahan. Memberikan posisi semi fowler pada pasien subjek I, II dan III, hasilnya pasien dibantu parawat untuk meninggikan posisi kepala pasien $30^{\circ}-45^{\circ}$.

Memberikan oksigen pada pasien subjek I, II dan III, hasilnya subjek I pemberian oksigen pada pasien sudah diberhentikan, subjek II pasien diberikan oksigen menggunakan nasal kanula dengan sebanyak 4 LPM dan subjek III Pemberian oksigen pada pasien sudah diberhentikan.

Memberikan terapi nebulizer pasien subjek I dan III, hasilnya subjek I terapi nebulizer pasien sudah dihentikan, subjek III terapi nebulizer pasien sudah dihentikan. Berkolaborasi pemberian obat pasien subjek I dan III, hasilnya subjek I pasien diberikan obat salbutamol tablet $2 \times 1 / 24$ jam melalui oral dan obat symbicort budesonide/formoterol 160/4.5 mcg/dose 120 doses, subjek II Pasien melakukan terapi nebulizer dengan menggunakan obat ventolin, flixotide dan $\mathrm{NaCl} 0,9 \%$ selama $15-20$ menit dan obat salbutamol tablet $3 \times 1 / 24 j a m$ melalui oral, subjek III pasien diberikan obat salbutamol tablet $2 \times 1 / 24$ jam melalui oral.

Mengajarkan mengidentifikasi dan menghindari pemicu pada pasien subjek I, II dan III, hasilnya subjek I diberikan health education dengan perawat, pasien mampu mengidentifikasi pemicu penyakit asmanya mucul yaitu debu dan asap, pasien juga akan berusaha menghindari pemicu penyakitnya, subjek II diberikan health education dengan perawat, pasien mampu mengidentifikasi pemicu penyakit asmanya mucul yaitu debu dan pasien juga akan berusaha menghindari pemicu penyakitnya, Subjek III diberikan health education dengan perawat, pasien mampu mengidentifikasi pemicu penyakit asmanya mucul yaitu debu dan pasien juga akan berusaha menghindari pemicu penyakitnya.

\section{Evaluasi Keperawatan}

Evaluasi merupakan suatu tahapan akhir dalam proses keperawatan untuk dapat menentukan keberhasilan dalam asuhan keperawatan. Pada dasarnya, evaluasi adalah suatu perbandingan status kesehatan pasien antara sebelum melakukan asuhan keperawatan dengan setelah melakukan asuhan keperawatan yang dapat dilihat dari hasil implementasi keperawatan, sejauh mana tujuan tercapai dan umpan balik dari tindakan yang diberikan (Tarwoto, Wartonah, 2015).

Dalam tahap evaluasi, penulis menggunakan metode SOAP. Evaluasi tindakan keperawatan yang dilakukan selama tiga hari sudah dilakukan secara komprehensif dengan rencana asuhan keperawatan serta telah berkolaborasi dengan tim kesehatan lainnya. Data yang didapatkan dari hasil evaluasi keadaan pasien berdasarkan kriteria hasil yang ingin dicapai.

Pada pasien subjek I sudah tidak sesak saat bernapas dan merasa lebih baik dari sebelumnya dengan hasil keadaan umum pasien baik, kesadaran composmentis, TD : 120/80 mmHg, N : 88 x/menit, S $: 36,3^{\circ} \mathrm{C}, \mathrm{P}: 18 \mathrm{x} /$ menit, kedalaman napas baik dan tidak terdapat suara napas tambahan. Pasien dibantu parawat untuk meninggikan posisi kepala pasien $30^{\circ}-45^{\circ}$. Pemberian oksigen pada pasien sudah diberhentikan. Nebulizer pasien sudah dihentikan. Pasien diberikan obat salbutamol tablet 2 $x$ 1/24jam melalui oral dan obat symbicort budesonide/formoterol 160/4.5 mcg/dose 120 doses. Setelah diberikan health education dengan perawat, pasien mampu mengidentifikasi pemicu penyakit asmanya mucul yaitu debu dan asap, pasien juga akan berusaha menghindari pemicu penyakitnya. Hal ini membuat kebutuhan oksigenasi pada pasien terpenuhi.

Pada pasien subjek II masih merasa sesak saat bernapas dan batuk berdahak disertai pilek dengan hasil keadaan umum pasien masih lemah, kesadaran composmentis, konsistensi sputum cair berwarna putih, TD : 120/80 mmHg, N : 90 x/menit, S : 360C, P : $26 \mathrm{x} /$ menit, kedalaman napas baik dan 
Vol. .... No......20....

e-issn : 2622-0148, p-issn : 2087-0035

terdapat bunyi napas tambahan yaitu ronchi. Pasien dibantu parawat untuk meninggikan posisi kepala pasien 30o-450. Pasien diberikan oksigen menggunakan nasal kanula dengan sebanyak 4 LPM. Pasien melakukan terapi nebulizer dengan menggunakan obat ventolin, flixotide dan $\mathrm{NaCl} 0,9 \%$ selama 15-20 menit. Pasien diberikan obat salbutamol tablet $3 \times 1 / 24$ jam melalui oral. Setelah diberikan health education dengan perawat, pasien mampu mengidentifikasi pemicu penyakit asmanya mucul yaitu debu dan pasien juga akan berusaha menghindari pemicu penyakitnya. Hal ini membuat kebutuhan oksigenasi pada pasien belum terpenuhi.

Pada pasien subjek III sudah lebih baik dan sudaah tidak merasa sesak saat bernapas dengan hasil keadaan umum pasien baik, kesadaran composmentis, TD : 120/80 mmHg, $\mathrm{N}: 86 \mathrm{x} /$ menit, S : 36,40C, P : $18 \mathrm{x} /$ menit, kedalaman napas baik dan tidak terdapat suara napas tambahan. Pasien dibantu parawat untuk meninggikan posisi kepala pasien 300-45o. Pemberian oksigen pada pasien sudah diberhentikan. Pasien diberikan obat salbutamol tablet $2 \times 1 / 24$ jam melalui oral. Setelah diberikan health education dengan perawat, pasien mampu mengidentifikasi pemicu penyakit asmanya mucul yaitu debu dan pasien juga akan berusaha menghindari pemicu penyakitnya. Hal ini membuat kebutuhan oksigenasi pada pasien terpenuhi.

\section{KESIMPULAN}

Kesimpulan dari hasil penelitian adalah :

1. Keluhan yang dirasakan pada pasien 1 dan 2 sama, sedangkan pasien 3 berbeda karena tidak mengalami batuk.

2. Diagnosa keperawatan dari ketiga pasien sama yaitu pola napas tidak efektif.
3. Rencana keperawatan dan tindakan yang dilakukan pada pasien 1 dan 2 sama, sedangkan pasien 3 berbeda karena memiliki keluhan sedikit berbeda.

4. Evaluasi keperawatan pada pasien 1 dan 3 sama dengan hasil bahwa pemenuhan kebutuhan oksigenasi terpenuhi, sedangkan pasien 2 berbeda dengan hasil pemenuhan kebutuhan oksigenasi belum terpenuhi.

\section{SARAN}

Beberapa hal yang disarankan adalah :

1. Kepada pasien agar tetap menghindari pemicu terjadinya penyakit asma bronkhialnya agar kasus kekmbuhan asma tidak berulang kembali. Kepada keluarga agar tetap membantu, mendampingi dan menyiapkan kebutuhan obat inhaler untuk mendapatkan penanganan pertama jika terjadi kekambuhan.

2. Kepada tenaga kesehatan khususnya perawat diharapkan untuk melanjutkan asuhan keperawatan yang sudah dikelola oleh penulis yang bertujuan untuk pemulihan kesehatan pasien dan dalam pemenuhan kebutuhan oksigenasi disesuaikan dengan kebutuhan pasien. Diharapkan pula pendampingan perawat pada kegiatan pasien dan meningkatkan pemberian edukasi kepada pasien dan keluarga pasien agar keluarga dapat terlibat aktif dalam proses pemulihan pasien.

3. Bagi masyarakat yang berada di sekitar pasien agar menciptakan suatu sistem pendukung dan melibatkan pasien dalam kegiatan sosial sesuai dengan kemampuan pasien. Melakukan kunjungan rumah dan piknik keluarga agar pasien tidak merasa sendirian dan merasa dirinya masih dihargai walaupun sakit-sakitan.

\section{DAFTAR PUSTAKA}

Anur Mitra, P., Rini, D. S., \& Tahir, R. (2018). Gambaran Asuhan Keperawatan Pada Pasien Asma Bronchial Dalam Pemenuhan Kebutuhan Oksigenasi Di Ruang Laika Waraka Rsud Bahteramas Kendari (Doctoral Dissertation, Poltekkes Kemenkes Kendari).

Clark, Margaret Varnel. (2013). Asma : Panduan Penatalaksanaan Klinis. Jakarta : EGC.

Harmoko \& Sujono Riyadi. (2012). Standard Operating Procedure dalam Praktik Klinik Keperawatan Dasar. Yogyakarta : Pustaka Pelajar.

Indar Asmarani, P., Tahir, R., \& Muhsinah, S. (2018). Asuhan Keperawatan Pada Pasien Asma Bronkial Dalam Pemenuhan Kebutuhan Oksigenasi Di Ruang Laikawaraka Rsu Bahteramas Provinsi Sulawesi Tenggara (Doctoral Dissertation, Poltekkes Kemenkes Kendari).

Kementrian Kesehatan Republik Indonesia. (2018). Hasil Utama RISKESDAS 2018. Jakarta : Balitbangkes.

Margaret Frej. (2015). Penilaian Kesadaran menurut Skala Glasgow : GCS. (n.d.). Institute IImu Saraf NHS Greater Glasgow dan Clyde.

Muttaqin, Arif. (2008). Buku Ajar Asuhan Keperawatan Klien dengan Gangguan Sistem Pernapasan. Jakarta : Salemba Medika.

Muttaqin, Arif. (2010). Pengkajian Keperawatan Aplikasi Pada Praktik Klinik. Jakarta : Salemba Medika.

NANDA. (2015). Aplikasi Asuhan Keperawatan Berdasarkan Diagnose Medis \& NANDA NIC - NOC. Jilid 1. Jogjakarta : Mediaction.

Padila. (2013). Asuhan Keperawatan Penyakit Dalam. Yogyakarta : Medical Book. 
Vol. .... No......20....

e-issn : 2622-0148, p-issn : 2087-0035

PPNI. (2016). Standar Diagnosis Keperawatan Indonesia : Definisi dan Indikator Diagnostik. Jakarta : Dewan Pengurus Pusat Persatuan Perawat Nasional Indonesia.

PPNI. (2018). Standar Intervensi Keperawatan Indonesia : Definisi dan Tindakan Keperawatan. Jakarta : Dewan Pengurus Pusat Persatuan Perawat Nasional Indonesia.

Rachmawati, R. E. (2013). Asuhan Keperawatan Pada Ny. S Dengan Gangguan Sistem Pernafasan Asma Bronkhiale Di Bangsal Melati Rsud Banyudono (Doctoral Dissertation, Universitas Muhammadiyah Surakarta).

Somantri, Irman. (2012). Asuhan Keperawatan pada Klien dengan Gangguan Sistem Pernapasan. Jakarta : Salemba Medika.

Tarwoto, Wartonah. (2015). Kebutuhan Dasar Manusia dan Proses Keperawatan. Jakarta : Salemba Medika.

Utami, H. W. (2016). Asuhan Keperawatan Pemenuhan Kebutuhan Oksigenasi Pada Ny. S Di Ruang Teratai Rumah Sakit Umum Daerah Dr. Soedirman Kebumen(Doctoral Dissertation, Stikes Muhammadiyah Gombong)..

Wahit, Iqbal Mubarak. (2008). Buku Ajar Kebutuhan Dasar Manusia. Jakarta : EGC.

Widodo, W. W. (2012). Studi Kasus Asuhan Keperawatan Pemenuhan Kebutuhan Oksigenasi Pada Tn. A Dengan Asma Bronkhial Di Ruang Mawar I Rsud Karanganyar. 